\title{
Development of Online Marketing During Coronavirus Epidemic
}

\author{
Zhichun Yang ${ }^{1}$ \\ ${ }^{1}$ School of Communication, The Ohio State University, Columbus 43220, United States
}

\begin{abstract}
At the beginning of 2020, the new coronavirus epidemic broke out globally. This epidemic has a serious impact on the country's economy, with a huge impact, a wide range and a deep degree. The epidemic has spread to a large extent and has brought serious harm to the world economy. But if we look at the impact of the epidemic on the national economy dialectically, opportunities and challenges should coexist. This article analyzes the opportunities and challenges faced by the Internet economy during the epidemic and the development of China's online marketing model during the epidemic. The combination of traditional business and emerging business is the focus of online marketing development. Through new media and big data analysis, the new online marketing model is no longer a simple e-mail advertisement and information on both sides of the article. The new network marketing model will become an important part of the economy in the post-epidemic era.
\end{abstract}

\section{INTRODUCTION}

Since the outbreak of the new coronavirus in 2020, China has been severely affected. Impact on the domestic economy in the first quarter. The global spread of the new crown pneumonia epidemic has brought a huge impact to the offline economy. Contactless services have become the current focus of business operations. Digital content production, including remote sales and online services, is taking the lead in the epidemic. The new media industry has developed in full swing in recent years, and the epidemic has come in handy now [1]. During the epidemic, the number of users going out and the surge in online financial demand have made it an unstoppable trend for online operations to replace offline processing. For most companies, traditional marketing methods may no longer be a temporary response in a special period. Online channels have become the focus of marketing. China's marketing methods are changing.

\section{2 analysis on the Reasons of Economic RECESSION DURING COVID-19}

\subsection{Increased online shopping}

China adopted a family quarantine policy at the beginning of the epidemic to prevent the spread of the virus during the epidemic. People cannot go out normally and their daily necessities such as food and drink must be purchased by community volunteers. From January to March, all households across the country were quarantined. People bought a large amount of daily necessities on online platforms, which promoted the development of the online economy and increased people's demand for online products [2].

\subsection{Stalled Market Service Industry}

The outbreak of the new coronavirus has led to the closure of physical stores in many places and fundamentally closed down basic living facilities, such as supermarkets, restaurants, and movie theaters. This has made a serious impact on the service industry [3]. Due to the need for epidemic prevention, many shops have been closed, restaurants and hotels are also temporarily closed. Various entertainment facilities have not been opened to people, and the entire social welfare system has basically been paralyzed. At this stage, the service industry as a whole accounts for nearly 50\% of China's GDP. Most people who were going to participate in the event forced the cancellation of the event. Induced labor, new consumption trends, upgraded consumption, tangible consumption and service consumption would face the challenge of insufficient effective demand [4].

The impact on the service industry will not only affect the country's economy, but also seriously affect personal income. The decline in the national economy has made lots of people unemployed and hindered the country's expansion. Store costs have increased over time, and even the closure of many supermarkets has caused conflicts of survival and social conflicts [5]. The service industry is the foundation of important economic development for all countries in the world, and it is related to people's most basic interests and lives. The impact of the service industry during the epidemic is huge. The market is stagnant and it is difficult to make offline purchases quickly. Therefore, online platforms are required to purchase related products. The popularity of online 
platforms has greatly promoted the development of online economy and online marketing.

\subsection{Broken Industrial Chain and Insufficient Inventory of Goods}

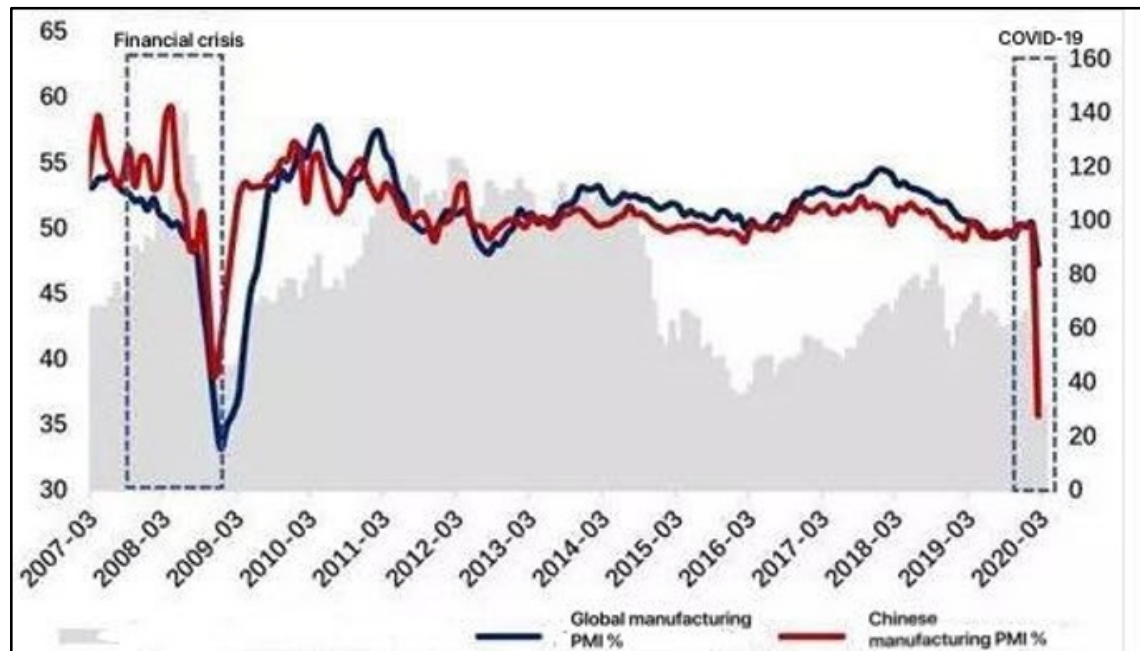

Figure 1. Comparison of the impact of the coronavirus epidemic on the PMI of Chinese manufacturing and the impact of the financial crisis on the PMI of the world's manufacturing industry [9]

The most serious consequence of the novel coronavirus outbreak is the shutdown of factories. After the outbreak of the new crown epidemic, factories had to stop production, and it was difficult to resume production in a short time. The closure of factories directly caused huge losses to the manufacturing industry and destroyed the industrial chain [6]. Especially in the industrial chain that is related to international trade, the number of orders from abroad has been significantly reduced, resulting in a lack of orders and stagnation of the industrial chain. Some companies have large orders and basically complete parts, but the supply of some major international parts cannot meet demand, so the entire industry chain is closed. Factory closures made it difficult to deliver products quickly and efficiently, leading to a shortage of online products.

\subsection{Traffic Stalls and Slow Logistics}

During the epidemic, public roads are strictly controlled, and the flow of people in different places must be graded accordingly. Especially in February 2020, many areas of our country closed down airplanes and railways and did not resume operations until March 2020. In addition to the corresponding online logistics network routes, the development of the online economy also requires corresponding logistics and transportation. In the case of the epidemic, road blockage in different regions will slow down the speed of logistics and have a significant impact on the development of logistics.

\section{Discussion}

\subsection{Video and Audio to Attract Users}

The new coronavirus epidemic has brought challenges to many industries, but it also provides opportunities to accelerate the economic development of China's online market and release the psychological needs of potential consumers. Just as SARS in 2002 triggered the growth of online sales in China, the outbreak of the new coronavirus indirectly led to the overall growth of the "family economy". Isolated from the rest of the world, a great amount of people want to reduce anxiety and take time to shift their focus from work to online entertainment.

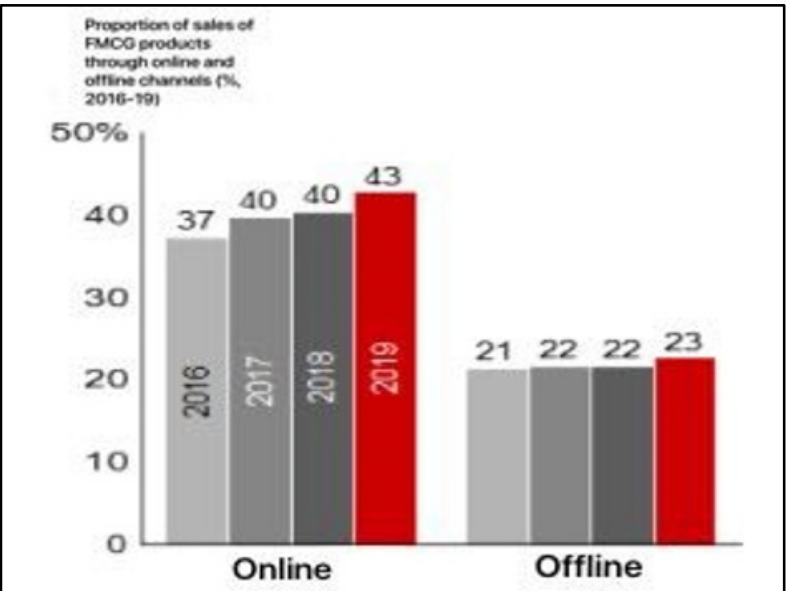

Figure 2. The epidemic has played a positive role in online shopping [10] 
Research shows that watching short video applications from Bilibili and TikTok has become one of the most popular entertainment methods, and the number of users has greatly increased [7].

At the same time, the Himalayas platform creatively invites art galleries and museums to establish "sound museums", which will transfer the offline space directly to the Internet and make it available to users. In the first quarter of 2020, revenue from the Himalaya platform will increase by $32 \%$, and revenue from entertainment and sports content broadcasting will also increase significantly. Therefore, the short video platform can effectively attract users and promote online marketing.

\subsection{New Trends in Online Marketing of "Live Broadcasting"}

The new online economy format has been further developed for "real-time commodity flow". In response to the new crown epidemic policy, people's travel has been restricted, stores have closed, supermarkets have shortened their business hours, and outdoor entertainment activities have almost ceased. In this case, Alibaba Group conducts product marketing through live broadcast and combining with TikTok's short video hotspots. For this reason, online marketing has been significantly improved and online sales have soared [8]. The way of live marketing also provides a new focus for those who stay at home for a long time.

Simultaneously, it is not just companies launching a live marketing model, but the Chinese government also adopts live marketing strategies to stimulate competition. In the process of live marketing, for many users, watching live product introductions is also an intuitive experience compared to variety shows. China CCTV News cooperated with Gome Retail to broadcast live on platforms such as Guo mei Store, Pin duo duo, and JD.com. Within 3 hours, product sales exceeded 500 million yuan, and the number of visitors exceeded 10 million. The development of the online economy, such as short video applications and real-time broadcasting, has temporarily replaced offline entertainment activities to reassure people at this special moment, and to some extent have avoided the economy caused by this new crown epidemic decline. The way of online marketing has changed from "online shopping" in the traditional sense to being led by enterprises, with big data analysis as the core. Through the analysis of user habits, determine user needs, and push related short videos or live broadcasts to users. This marketing method has formed a fusion with the new media industry.

\subsection{Development of online education}

In the short term, due to the interruption of offline education of educational institutions, the new crown epidemic has had a significant impact on educational institutions, especially offline educational institutions. The school postponed the spring semester. Therefore, many online education courses need to be established to achieve previous classroom teaching goals, which bring convenience to online education and cover many high-quality educational resources that are not limited by time and space. According to relevant data, China's online education market developed rapidly during the popular period, which also promoted the rapid development and application of online education. Online education platforms provide important opportunities for continuous innovation and development opportunities, and avoid face-to-face education and protect the safety of teachers and students. At the same time, with the help of a batch of mature online conference platforms such as zoom and voov, the distant education becomes more technically accessible. Mature technology makes the large-scale development of online education possible. Online marketing of educational institutions has grown during the epidemic.

\subsection{Increased game industry's income and the number of online users}

The epidemic has also brought good benefits to the game industry. During this period, new downloads and revenue sources of game products owned by various game companies have grown rapidly. Throughout the U. S. stock market, game companies such as Blizzard Activision have seen their share prices have increased significantly during the epidemic. In the first quarter, Tencent from China reached 2 billion in its game business and became a giant in the Chinese game industry due to the epidemic. Due to restrictions on the scope of activities, people spend more time at home during the epidemic, which made online games become an important way of passing time. Combined with the large-scale publicity of the game industry, online games have developed rapidly through this period.

\section{Conclusion}

The online mode has the advantages of online transactions and personal distribution, which can effectively meet people's needs and solve people's payment problems. Many people who cannot go out increasingly rely on the online economy, which further increases their online shopping habits. During the epidemic, online marketing methods have undergone diversified changes. For instance, game platforms have adopted a price reduction or even free strategy to attract a large number of users.

In addition, the short video industry and the live broadcast industry have formed comprehensive cooperation with traditional online shopping platforms. It relies on new media and big data analysis to form a complete marketing process from publicity to retail. The new online marketing model will become an important component in economy. Since the field of online marketing is very wide and there are so many forms, this article may have a new marketing model that is missing. If conditions permit, follow-up research will analyze more the development of online marketing models. 


\section{ACKNOWLEDGMENT}

First of all, I sincerely thank all the teachers who provided help notifications! The careful guidance and careful notification arrangements of the teachers for my study have benefited me for life. Under the guidance of the teachers, I can finish this paper. Thanks to all the teachers who have helped me! The professional knowledge you impart to me is the source of my continuous improvement and the basis for completing this thesis.

\section{REFERENCES}

1. Gilead Sciences Inc.; European Commission Grants Conditional Marketing Authorization for Gilead's Veklury ${ }^{\circledR}$ remdesivir for the Treatment of COVID-19[J]. Medical Letter on the CDC \& FDA, 2020.

2. Liu Yajun. An analysis of the functional form of the online exhibition in the context of the live broadcast. Business economy, 2020 (07): 97-98 plus 103. 2020.

3. Wick. Overseas book industry channel construction under the epidemic: seeking multi-program innovation initiatives to actively get out of trouble. International Publishing Weekly, 2020-07-20 (008).

4. Fu Wenwei, Liu Xiuzhong. How to carry out archival work online during the outbreak . . archives, 2020(07): 60-62.

5. Hongwei He, Lloyd Harris. The impact of Covid-19 pandemic on corporate social responsibility and marketing philosophy[J]. Journal of Business Research, 2020, 116.

6. Maura L. Scott, Kelly D. Martin, Joshua L. Wiener, Am Scholder Ellen, Scot Burton. The COVID-19 Pandemic at the Intersection of Marketing and Public Policy[J]. Journal of Public Policy \& Marketing, 2020, 39(3).

7. Nano Logix Inc.: Nano Logix Seeks Development \& Marketing Partner for Their Sub 1-Hour COVID-19 Detection Tests[J]. Medical Letter on the CDC \& FDA, 2020.

8. Loudoun Go; Loudoun Entrepreneurs Expedite Launch of Loudoun County Marketing Platform and Online Farmer's Market In Response To COVID-19[J]. Medical Letter on the CDC \& FDA, 2020.

9. Online Available:

http://n.sinaimg.cn/finance/crawl/790/w500h290/202 00310/1f1a-iqrhckn1766129.jpg [Accessed on September 1st, 2020]

10. Online Available: https://www.kantarworldpanel.com/assets/emb_imag es/9/0629-33.png [Accessed on September 1st, 2020] 